\title{
A comparison between the attachment styles and Mate-selection criteria in Urban and rural girls
}

\author{
Atefe Najafizadeh ${ }^{1, \star}$, Nesa Samaeelvand ${ }^{2}$, Hamid Yousefi $^{3}$, \\ Mojtabla Parhizgari $^{4}$, Marjan Keiaei ${ }^{5}$ \\ ${ }^{1}$ Department of General Psychology, Allameh Tabatabai University, Tehran, Iran \\ ${ }^{2}$ Department of Counseling and Guidance, Kermanshah Sciences and Research Branch, \\ Islamic Azad University, Kermanshah, Iran \\ ${ }^{3}$ Department of Psychology, Ilam Branch, Islamic Azad University, Ilam, Iran \\ ${ }^{4}$ Department of Business Management, Shiraz Branch, Science - Applied University, Shiraz, Iran \\ ${ }^{5}$ Department of General Psychology, Tonekabon Branch, Islamic Azad University, Tonekabon, Iran \\ *E-mail address: Atefeh.najafizadeh@yahoo.con
}

\begin{abstract}
The intent of this study was to compare attachment styles and Mate-selection criteria in urban and rural girls. The participant in this study included all the urban and rural girls (17-23 year old) of Ghorveh city in 2013-2014. A Sample consisting of 100 girls (50 urban and 50 rural) were selected using simple random sampling method. These two groups were equally matched on the basis of age, educational and economic status. Measuring instrument was the adult attachment scale, contains 21 questions, and researcher made questionnaire, titled as the mate-selection criteria contains 75 questions were applied. To analyze the data, frequency, percentage, average and the test were applied. The results indicated that there is significant difference between the rural and urban girls with respect to the secure attachment style. Also the results reveal that there is a no difference between the anxiety attachment style, avoidance attachment style and Mate-selection criteria of the two groups (rural and urban girls).
\end{abstract}

Keywords: attachment styles; Mate-selection criteria; urban and rural girls

\section{INTRODUCTION}

Urbanism today has become the dominant style of life in the world and Iran. The number of people residing in cities in Iran over the past four decades has risen seven times and has reached 42 million people in 2001 from slightly less than 6 million in 1957. Meantime, at the same time, the Iranian population has increased three fold. Discussion over what impacts urbanism has on peoples' behavior and attitudes is one of the main and wellestablished subjects of urban issues studies (Haghighatian, 2012). 
Man in light of the grace of "reason" and "authority" continuously "chooses" and then youth due to being in a critical stage of development and growth face with complex decisions and important choices. Of the important choices in this period of time is "mate selection". The importance of "mate selection" -interpreted as the cornerstone of "marriage" and the formation of "family" could be found in the importance of "family" and "health" of the society (Mallahi et al, 2013). Because "family" is considered a fundamental basis of the society and it is implicit that the "health of the society" links with the "health of the family". In fact, the marriage as the primary cornerstone of the family is a legal and emotional bond in the course of life between two people that bands man and woman together. An affair in which man has entered with a choice last for about half a century (Mallahi et al, 2013). In fact, "marriage" is the most important factor in the creation of a healthy society (Friedman, 2007). In which "mate selection" occurs and the success at the other stages of life is dependent on the success of this stage. Research over "marriage" are indicative of the fact that the cause of most of the marital problems and families go back to an "inappropriate choice" of one or several effective factors in the "marriage"(Markman, 2008). Thus, inappropriate choices of the mate selection criteria" are regarded as the main reasons of gradual decline of the marital life (Simon, 2008). The" absence of appropriate criteria for selecting a mate "and not giving importance to "personality characteristics of the mate" mare major reasons of "divorce"( Mallahi et al, 2013).

Urban development, uncontrolled expansion of the population, migration from rural places to large cities and other factors have led to a qualitative and quantitative increase of social problems in IRAN (Fakhraee, 2003). Generally speaking, social problems refer to studying social chaos and disorders (Saleemi, 2001). In other words, social deviance means behaviors which are not consistent with social norms and criteria. When the number of crimes and delinquency exceeds a certain limit, it could be called a social problem (Mohamadi, 2004).

Attachment styles are of intrapersonal sources that can adjust stress and inability levels in adverse conditions and it also causes negative effects of stress looks pale. According to various studies, attachment style is important predictor in mental health (Linley\& Joseph, 2004).

In evolutionary psychology, the emotional relationship between infant and mother is called attachment. Attachment begins in infancy and it is stable over time (Bowlby, 1969). Bowlby discovered the process of forming and breaking the emotional ties. He particularly has discussed exciting attachment of infants to their first caregivers and their exciting distress at the time of their separation (Bowlby, 1969, 1973, 1980). Attachment theory sees humans as a social creature that has the capacity communicate with other humans. Bowlby believes that attachment in child-parent relationship can be transmitted to adult romance relationship and it can affects cognition, emotion and behavior in life. Any damage to attachment relationship can lead to subsequent damage and risks. According to this, security can be described as the core of attachment system in relationships. A secure relationship is established with someone who we are attached ( Bowlby, 1982). The way someone is attached to his or her mother can affects the way he or she is attached to others during his or her life span (Lugo \& Hershy, 1979). What determines attachment feelings in adults is that it is based on feeling of safety, feeling of being needed, and feeling the power of generosity. And lack of them leads to loneliness and anxiety (Feeney \& Noller, 1991). Hazan \& Shavar (1987) founded adult attachment based on Bowlby attachment theory. They have described adult attachment in forms: 
A: Internal representations or patterns that direct interpersonal behavior and information processing.

B: Specific strategies and practices that people use for their own security. Generally, based on the conducted results on infancy attachment styles (Ainsworth et al, 1978), Hazan \& Shaver (1987) offered adult attachment styles in three classes:

1-secure: secure individuals are comfortable in establishing intimate relationships. They tend to depend on others for support and they are sure that others like them. Attachment figures describe themselves as warm people. They have a positive image of themselves and have positive expectations of others.

2-Anxious-ambivalent: these individuals have intense desire to establish close relationships. But they are also worrying of being rejected. They consider their acceptance on the part of others as a prerequisite to feel good. These people have a negative effect of themselves and they have negative effects towards others.

3- Avoidant: in these people' point of views the worthwhile matter is self- reliance. When it is likely to be rejected by others, they maintain a positive image of themselves by denial. Avoidant individuals have negative expectations of and negative attitudes toward others.

One of the influential theoretical approaches regarding interpersonal interactions is the theory of attachment. Bowlby states (1969), the nature of the first intimate relationship (mother - child), determines the nature of the persons' intimate relationship throughout life. Hazan and Shaver (1987, 1994), applied these ideas directly in the adulthood relationship and stated the relationship satisfaction in the adulthood period largely depends on satisfying the initial basic needs including comfort, protection and prosperity. In this research problems related to attachment and its relationship with running away, family, and some other factors like age, parents' education, and the numbers of family members have been investigated. Whitbeck et al (1999) maintain children and teenagers growing up in unorganized families, or those sexually abused will eventually run away from home and may be drawn into prostitution. Also, in their research, Thrane et al (2006), showed families' abusing children is one of the affective factors in running away.

Also, while investigating the relationships among the couples having affairs in the monogamous marriages, they found out that, the "financial dominance" for women and the "social dominance" for men contributes to their satisfaction of their lives. However, both groups regard "understanding" as the strongest factor in retaining the present and future relations and consider the "lack of the couples' understanding" as the lone factor of collapse of the marital relations (Mallahi et al, 2013). Yazdani (1994), in a research over the female students of the Isfahan medical sciences university concluded that people paid highest attention to the age difference with future mate, parental views, mates' physical appearance , their attractiveness and lastly their educational levels being the same respectively for choosing the mate (Qouted by Husseini et al, 2006). In the research by Moghaddas Jafari, and Majidi (1998), the results of the investigation of the Kerman university students ' attitude to marriage suggested that $\% 73.2$ of the students under study have regarded "higher literacy level" and " understanding" as the most important marriage criterion with the students and in contrast they have considered the " physical characteristics of the mate " as the last criterion and from among them the " appearance status" as the least important criterion. In research Zanjanitebbi (2000), titled as "investigating the effects of the students' mate selection criteria on the familial satisfaction " statistical reports indicated that there is a significant relationship between the four variables of the "couples' social origin", couples' religious similarity", "couples' parents' social stature" and" couples' earning level" with the dependant variable of 
the " life satisfaction". Findings by Zareshahabadi (2002), with regards to the mate selection criteria of the Yazd students revealed that women attach least importance to the "physical attractiveness" (\%76), and in contrast, pay highest attention to the "religious criteria" (\%90.8) and while they consider as important "being citizenship" (\%55.4) and "having a similar language and community" (\%4406). The research by Husseini et al (2006), the marrying couples of the city of Tehran have considered the "mental health of their mates" as the most important priority of their mate choosing from among the five fold indices of the priority of choosing a mate, including "family status", "physical appearance", "mental health of the partner", "social-economic status: and the "social-cultural status" . In the research by Mehrabi zadeh Honarmand and Davoodi (2006), the results of identifying the mate selection criteria of the single students of the Shahid Chamran University indicated that the mate selection criteria of the students are grouped into three categories of "personal characteristics', "similarities" and "social-economic status". The aim of this research is to compare the attachment styles (Secure, Anxious-ambivalent, and Avoidant) and Mate-selection criteria between the two groups of urban and rural girls.

\section{METHODOLOGY}

The participant in this study included all the urban and rural girls (17-23 year old) of Ghorveh city in 2013-2014. A Sample consisting of 100 girls (50 urban and 50 rural) were selected using simple random sampling method.

In this research, compare the attachment styles (Secure, Anxious-ambivalent, and Avoidant) and Mate-selection criteria between the two groups of urban and rural girls has been investigated based on adult attachment questionnaire of Hazan \& Shaver, and researcher made questionnaire, titled as the mate-selection criteria contains 75 question.

A) Mate selection criteria questionnaire, a researcher made questionnaire titled as "the questionnaire of the Iranian youth mate selection criteria" was used. This questionnaire was formulated by the researchers with the aim of measuring the Iranian youth mate selection criteria that includes 75 items in the areas of appearance and physical, social and moral, marriage skills and financial power, similarity and agreement, family status, and health and medical criteria. The validity of the questionnaire of the mate selection criteria is of a content type and for the reliability of the questionnaire; the alpha Cronbach method was used. Investigations show a reliability degree of $0 / 83$ for the group living in Iran of $0 / 93$. Thus, the statistical results are indicative of a higher reliability of the mentioned questionnaire fir measuring the mate selection criteria of the Iranian youth living in Iran. Questionnaire questions are in the Likert style, in which people-based on the importance they give to each of the criteria- give to each of the items from the lowest score (0) to the highest score (3). In formulating this questionnaire three measures were adopted in parallel: (1) Investigating the research literature related to the mate selection criteria by the researchers at different universities inside the country (2) Consultation with the referee and advisor professors and consultation with psychologists (3) Feedback by the Iranian students living in the IRAN. In the section of the students' feedback, the researcher formulated a form and based on which he demanded the students that they list at least 10 major criteria for the future mate selection. This form was completed by 20 Iranian students inside the country and 20 students in Germany and hence, information was obtained, extracted and categorized. Hence, according to the categorized criteria from the viewpoint of these 40 students as well as the information 
and data of the past literature, the primary list of the Iranian mate selection criteria was formulated. After reviewing the students' feedbacks and benefitting from the views of the referee professor and his psychologist colleagues with respect to excluding the overlap of the instances, the literary and content term of the material, ultimately, the 75 item questionnaire of the Iranian youth mate selection criteria, including the six fold factors of the mating process was formulated like the following:

Appearance and physical criteria: They include skin color, attractiveness, being slim, being communicative, well-spoken, and lastly fitness.

Social and moral criteria: They include sanity, conscientiousness, lack of the history of emotional relations with the opposite sex, politeness, self confidence, popularity, being economical, obedience to religious beliefs, grace and following ethical principles, neatness, lack of hatred, being trustable, being industrious, talented and man of taste and art, joviality, humbleness, frankness, fame, lack of ill record, welcome promises, and lastly liking for consultation.

Marriage skills and financial status criteria: They include type of the job, being financially independent from the family, having appropriate facilities for a new life, the ability to hold appropriate ceremonies for the marriage, respect for the rights of the mate, taking into account the mate's views and ideas, fidelity, understanding of the problems, being thankful to the mate, the ability to admit5 to mistakes, the ability to get along with the problems, interest in having children, and having special skills like driving and being a housewife.

Agreement and similarity criteria: They include age proportion, education being equal, being of the same religious background, mutual love and interest, being citizen, the closeness of interests and political inclinations, and being of the same linguistic and racial background.

Family status criteria: They include nobility and reputation of the mate family, the two families being equal in terms of economic status, both families being religious and cultured, the consent and agreement of the two families with the marriage, lower number of the sisters and brothers of the mate family, good financial status of the mate family, higher level of education of the mate family, absence of the history of infertility in the mate family, lack of special and terminal diseases in the mate family, not having mutilated and disabled children in the mate family, the mate being the sole child and being relative of the mate.

Medical and health criteria of the future mate: They include being strong and athlete, full physical health, lack of physical disability and mutilations, being intelligent, lack of using drugs and alcohol, and lack of smoking.

B) Adult attachment questionnaire (AAQ): this scale was created in 1987 using Hazan \& Shaver attachment test material and was normalized in the case of Tehran University students. This questionnaire consists of two parts: in the first part, three attachment styles, safe, unsafe, ambivalent distinguished are based on 21 questions on a Likert scale of five degrees (none $=1$, low $=2$, average $=3$, great $=4$, very great $=5$ ). Cronbach's alpha coefficient of questions relate to each scale, safe, unsafe, and ambivalent scales studied by Besharat were $\alpha=.74$ and $\alpha=.72$ respectively in the case of a 240-person student sample. The second part involves a subject that determines its attachment style by selecting one option from the three options that describe three kinds of attachment. Correlation coefficient between subjects' scores on the two parts of questionnaire was $r=.85, p<.01$ and $r=.87, p<.01$ for female and male subjects, respectively (Besharat et al, 2006). 


\section{FINDINGS}

The average and standard deviation of the Secure, avoidance and anxiety attachment styles and Mate-selection criteria between the two groups of girls (rural and urban) are provided in the following table 1

Table 1. Group differences to compare of attachment styles and Mate-selection criteria of the two groups.

\begin{tabular}{|c|c|c|c|c|c|c|c|}
\hline \multirow[b]{2}{*}{ Variable } & \multicolumn{2}{|c|}{ Rural } & \multicolumn{2}{|c|}{ Urban } & \multirow[b]{2}{*}{$\begin{array}{l}\text { Freedom } \\
\text { degree }\end{array}$} & \multirow[b]{2}{*}{$\mathrm{t}$} & \multirow[b]{2}{*}{ Sig. } \\
\hline & Mean & $\begin{array}{l}\text { Standard } \\
\text { deviation }\end{array}$ & Mean & $\begin{array}{l}\text { Standard } \\
\text { deviation }\end{array}$ & & & \\
\hline Secure & 31.47 & 7.1 & 26.61 & 6.24 & 98 & 3.64 & 0.002 \\
\hline Unsafe(Avoidant) & 24.56 & 6.32 & 25.51 & 7.31 & 98 & 0.69 & 0.42 \\
\hline Unsafe(Anxiety) & 24.92 & 6.7 & 26.7 & 7.11 & 98 & 1.29 & 0.301 \\
\hline $\begin{array}{l}\text { Mate-selection } \\
\text { criteria }\end{array}$ & 161.81 & 17.2 & 170.8 & 19.77 & 98 & 2.42 & 0.063 \\
\hline
\end{tabular}

The results of the test in table (1) show that there is a significant difference between the rural and urban girls with respect to the secure attachment style. An investigation of the secure style of the two groups shows that rural girls are in a higher level compared to the urban girls in terms of security. Also, findings reveal that there is no difference between the two groups with regards to the avoidant attachment style. Also, findings reveal that there is no difference between the two groups with regards to the ambivalent attachment style (Anxiety). To investigate the security of the attachment style in the two groups of girls, the insecure attachment style, i.e. ambivalence and avoidance styles were combined and then we investigated the insecurity of the attachment into two groups.

Also the results reveal that there is a no difference between the Mate-selection criteria of the two groups (rural and urban girls).

\section{DISCUSSION AND CONCLUSION}

Findings of the research showed that there is a significant difference between the rural and urban girls with respect to the secure attachment style. And also findings of the research showed that there is a no difference between the rural and urban girls with respect to the unsafe (Avoidant) attachment styles, unsafe (ambivalent -anxious-ambivalent) and Mateselection criteria. According to the obtained results in this research, the average avoidance and anxiety scores, age of father and mother, their education levels, number of family members, have been significantly higher in urban girls than rural girls. The ECR-R evaluated avoidance and anxiety attachment styles. The results of this research are consistent with those of Roberts et al, and Bartholomew and Shaver. Roberts et al, in their research showed there is a relationship between insecure attachment styles including double-wing and avoidance and anxiety and depression. Also, Bartholomew and Shaver(1996), stated in their research, people having avoidance insecure attachment styles, face problems in being intimate and relying on others. They maintained through attachment styles, one can predict interpersonal problems and the feeling of lack of security in adults. Feeny et al (1994), in their research on the 
relationship between attachment styles and self-esteem, anxiety and stress indicated that insecure attachment styles are correlated with maximum stress and minimum self-esteem levels. Allen et al, (2002), also showed, that the correlation pattern of adolescents is investigated as the predictor of the development level of social skills as well as delinquency in midadolescence. Findings revealed, the secure attachment style predicts the increase of social skills from 17 to 20 years of age. As opposed to the insecure attachment style the double-wing predicts an increasing trend of crimes during the same period. Armed with this attachment style and in case of having mother with a high autonomous educational style, adolescents show a more reduction in the social skills and an increase in crime which cause them to have deviant behavior. The available findings are in line with the results of this research indicating when the adolescent experiences a high level of secure attachment could have little anxiety and stress in facing with problems he faces in life. Adolescents who experience anxious and insecure attachment style have little self-confidence compared to the rest of the society and react negatively to others. When avoidant insecure people find themselves in social relationships under scrutiny, face stress, anxiety and mental imbalance. They fear being rejected by others and principally don't communicate with others. In fact, by avoiding from communicating with others, they try to save themselves from the feeling of frustration. There has not been done any research in this regard in Ghorveh on individuals' lack of access to IQ, the exact economic and cultural state and their effect on attachment style and Mate-selection criteria, the lack of knowledge about how much they enjoy an appropriate and principled education, and the lack of documentary access regarding students' emotional problems. According to the Kurdish language and culture, this research can lead to future research in this regard. It is recommended that more researches with more samples, involving more people with different cultures be performed so that they can be generalized. Since this research was conducted in Kurdistan it is advised that such papers are conducted in other cities, provinces with various ethnic groups and cultures. Of other limitations of the research was that the paper was performed in Ghorveh and in generalizing the results, caution should be made.

\section{References}

[1] Ainsworth, M. D., Blehar, M.C, Waters, E., \& Wall, S (1978). Pattern of attachment: A psychological study of the strange situation. Tilsdale, N. J: Elbaum .

[2] Allen, P,;Marsh,P.;McFarland,C.;McElhaney,\& Land, D.J. (2002).Attachment and Autonomy as Predictors of the Development of social skills and Delinquency Midadolescence.Journal of consulting and clinical psychology, (70)1, 56-66.

[3] Bartholomew, K, Shaver, P.(1996). Method of Assessing Adult Attachment: Do They converge? Measurement Issues 2: 25-45.

[4] Besharat, M.A., Karimi. K., \& Rahiminejad, A. (2006). The studying of relationship between attachment style and personality phase. J Psychology and cultural science; 36(1\&2): 37 - 55 .

[5] Bowlby, J. (1969). Attachment and loss. Voll Attachment, London the Hogarth press and the institute of psycho- Analysis.

[6] Bowlby, J. (1969).Attachment and loss Vol:1Attachment.NewYork:Basic Books.

[7] Bowlby, J. (1982). Attachment and loss. 2nd ed. New York: Basic Books: 54-5. 
[8] Bowlby J. (1973). attachment and loss, vo1-2-separtion, anxiety-Yand angel. New York. Basic book

[9] Bowlby J. (1980). attachment and lossoadhesand depression. New York. Basic book.

[10] Fakhraee, Fareeba (2003), Investigatinf psychological characteristics including emotions, intelligence, self-esteem, and the identity of prostitutes compared to normal women, PhD desertation on psychology. Medical Sciences University of Mashhad.

[11] Feeney J.A.,Noller.p.,\& Hanrahan M. (1994). Assessing Adult Attachment in spelling M.B. And Berhman, W.H. Attachment in Adults: clinical and Development perspectives. Guil ford Press N.Y.

[12] Feeney J.A., \& Noller P. (1991).Attachment Lifestyle predictor of adultRomantik Relationship. Journal of child psychology and psychiatry. Vol.58, 282 - 297.

[13] Friedman M. (2007). Differences in meta selection. Journal of personality and social psychology, 130: 81-89.

[14] Haghighatian M. (2012). Effects of urbanization on social relations in Bushehr. Journal of Urban Studies and Planning, 3(8): 39-50.

[15] Hazan, C. \& Shaver P.R.(1994). Attachment as an organized framework for research on close relationships. Psychological Inquiry, 5: 1-22.

[16] Hazan, C., \& Shaver, P. (1987). Conceptualizing romantic love as an attachment process, Journal of Personality and Social Psychology, 52,511-524.

[17] Hazen, C., \&Shaver,P.R.(1987).Romantical love conceptualized as an attachment process. Journal of Personality and Social Psychology, 52: 511-524.

[18] Husseini, M., Mohamadi, M., Yaghmaee, F., Alavimajd, H., \& Yazdjerdi, M. (2006). Investigating the criteria of mate selection by women on the verge of marriage at the health care centers of the cities that are affiliates to the medical sciences university's of Tehran, Journal of nursing and obstetrics faculty of Shahid Beheshti, 16(53): 19-28.

[19] Linley, P. A., \& Joseph, S. (2004). Positive change following trauma and adversity: A review. J Trauma Stress; 17: 11-21.

[20] Lugo, J.O .Q., \& Hershy. CL. (1979). Human Development Macmillan publishing.

[21] Mallahi, L., Kamarzarin, H., Safarnia, M., Taghi Zade, M. E., \& Khaledian, M. (2013). A comparative investigation of the mate selection criteria of the 18-35 yearold unmarried Iranian students living in the cities of Tehran (Iran) and Berlin (Germany). Science road journal, 1(3): 85-96.

[22] Markman, H. J. (2008).Preventing marital distress through communication and conflict management training. Journal of counseling and clinical psychology,111: 7078.

[23] Mehrabi zadeh Honarmand, M., \& Davoodi, I. (2006). Mate-selection criteria for single students Shahid Chamran University. Journal of Educational and Psychological Studies, University of Isfahan, 2(6): 23-44.

[24] Moghaddas Jafari, M. H., \& Majidi, M. H. (1998). Students' Attitudes about marriage. Journal of Culture and Literature. 11: 95-104. 
[25] Mohamadi , Z. (2004).Social investigations of women in the 90s. Women cultural and social council publication.

[26] Saleemi , M. (2001).Sociology of delinquency, Pezhoheshkade publication,

[27] Thrane, L., Lisa.E.,Hoyt, D., Danny R., Les. B., \& Yoder, Kevin, A.(2006).Impact family on running away,deviance, and street victimization among homeless ruler and urban youth.child Abuse \& Neglect,30: 1117-1128.

[28] Whitbeck, L.B.,Hoyt D.R and Youder K.A.(1999).A risk amplification model of victimization and depressive symptoms among runaway and homeless adolescents. American Journal of Community Psychology.27: 296-273.

[29] Yazdani, M. (1996). Investigation the facilitating factors of marriage during the students' academic courses from the viewpoint of Tabriz University students , Medical science university of Tabriz.

[30] Zanjanitebbi, A. (2000). Investigating the effect of the mate selection criteria among 5the students on the satisfaction of life, M.A. thesis, University of Allame tabatabee.

[31] Zareshahabadi, A., \& Zareshahabadi, A. (2002). Investigating the mating criteria among the students of the university of Yazd, Scientific and research periodical of population, $2(39,40): 35-44$. 